\title{
SOCIAL RESPONSIBILITY OF A STOCK EXCHANGE: CORPORATE GOVERNANCE AT BORSA ISTANBUL
}

\author{
A. Can Inci \\ Bryant University, RI, USA
}

\begin{abstract}
Accentuated intraday volatility and uncertainty leads to mispricing, inefficiency, and the potential unfair treatment of some market participants. As an important financial institution, the stock exchange is required to find mechanisms to reduce volatility for good corporate governance and for social responsibility. In this paper, one such mechanism, closing call auction, is explored in the actively traded industrials sector of the emerging Borsa Istanbul. Evidence of the successful implementation of the mechanism is provided. Volatility decreases and efficiency of the prices increases after the implementation of the closing call auction. The exchange executives' positive engagement in good corporate governance is documented and is suggested to other stock exchanges as a social responsibility instrument.
\end{abstract}

Keywords: accentuated volatility, corporate governance, corporate social responsibility, emerging markets, market efficiency

DOI: http://dx.doi.org/10.15549/jeecar.v7i1.374

\section{INTRODUCTION}

The social responsibility theory involves enacting policies that endorses a balance between profit maximization of a business for its stakeholders and benefiting the society as a whole. Social responsibility becomes more meaningful when a company voluntarily establishes its internal policies, as opposed to regulation through the government. Therefore, businesses are feeling more and more encouraged to act in a manner that benefits all the participants of the economy, in addition to maximizing shareholder value. Corporate social responsibility aims to diminish practices that harm the society, and to implement policies that benefit everybody (Campbell, 2007).
One of the most important financial institutions in a society is the stock exchange, where shares of publicly traded corporations are exchanged between market participants. The stock exchange administrators have the goal of making sure that all the participants are treated fairly and equally in terms of access to the markets and in terms of the execution of the trades. This primary goal is consistent with the corporate social responsibility theory. The exchange administrators monitor the market to make sure that illegal informed trading does not take place, irrational trading behavior does not dominate the market, and unreasonable volatility does not exist. In other words, as mentioned in Ching and Tardelli (2015), the administrators want to make the exchange 
efficient, where the prices are stable, and they correctly reflect the values of the securities.

Stock market exchanges in developed countries have long-established rules and regulations. For example, the New York Stock Exchange has a circuit breaker mechanism to reduce overall volatility and to encourage traders to act rationally, especially in a panic environment. Another mechanism is an auction system before the market opens in the morning. By taking into account the order imbalances, the accumulated buy and sell orders are matched to determine the optimal execution price to reduce volatility when the stock market opens in the morning. Volatility is highly undesirable because it brings in inefficiency, mispricing, uncertainty, and unequal treatment of market participants since inexperienced traders are taken advantage of. The call auction mechanism is an example of the corporate social responsibility of exchange administrators because by increasing efficiency and equal treatment of market participants, the society as a whole benefits (Francioni and Schwartz, 2017).

The main motivation of the study is to examine how Borsa Istanbul, as one of the most important financial institutions in Turkey, approaches corporate governance and social responsibility. Whether the Borsa Istanbul regulators implemented any mechanisms to reduce intraday volatility and therefore achieved social equity is investigated. The analyses concentrate on the industrials sector of Borsa Istanbul. Currently the largest and the most important sector of the Turkish economy is the industrials sector, with companies that are actively traded stocks at the stock exchange without any liquidity frictions. The second motivation for the study is to shed light on whether such mechanisms have been useful and successful. Exchange managers at Borsa Istanbul introduced a closing call auction mechanism to reduce volatility near the closure of the market each day. The paper provides evidence of the effectiveness of the closing call auction mechanism for the industrials sector stocks. The third and final motivation of the investigation is to suggest recommendations to regulators in other emerging- and frontier-country equity markets since Borsa Istanbul is a good representative for such markets.

The rest of the paper is organized as follows. Section 2 is the literature review on the relevant corporate governance studies and intraday volatility research. Section 3 provides information about Borsa Istanbul and about the industrials sectors. The corporate governance practices implemented by the Borsa Istanbul administrators are described. Section 4 is about the data and the methodology. Section 5 presents the discussion of the results. Conclusion follows.

\section{LITERATURE REVIEW}

\section{Corporate Governance and Social Responsibility}

Social responsibility and corporate governance both focus on the ethical practices in a business. Social responsibility is more of a policy or an obligation to the community with the goal of performing beneficial activities for all. This means that a corporation should take into account the social, environmental, economic, and human rights perspectives in business dealings and operations. On the other hand, good corporate governance is central to any successful business. It is necessary for an organization to maintain good legal and ethical standing for the shareholders, regulators, and the wider community, in addition to the traditional goals of profitability and growth.

Corporate social responsibility has been in debate since the 1950s, and Carroll (1999) provides a comprehensive survey of previous work. While earlier studies discuss the pros (Campbell, 2007) and cons (Friedman, 2008) of social responsibility and the culture, the overall evidence over the last two decades in El Ghoul et al. (2011) and in others has shown the necessity of social responsibility for a corporation's performance. Studies about corporate governance in emerging countries such as India (Sarkar and Sarkar, 2000), also point out the importance of good corporate governance for success. Investment portfolios and strategies are now commonly designed by taking into account corporate governance and social responsibility factors as discussed in Kempf and Osthoff (2007). 
Social responsibility and corporate governance of a stock exchange is of essential importance because the exchange is one of the most fundamental financial institutions in an economy. The rules and mechanisms adopted by stock exchanges for good corporate governance have been examined in Abrahamand and Kannappan (2018) and Ching and Tardelli (2015), among others. These studies have mostly focused on the corporate structure of the administration of the exchange and have compared corporate governance mechanisms between difference exchanges. In this paper, the main focus will be on the success of the mechanisms implemented by the exchange administrators to alleviate inefficiencies, mispricings, and potential unfair treatment of market participants.

\section{Intraday Volatility and Stock Exchange Corporate Responsibility}

Volatility (or uncertainty) is an undesirable medium for stock trading because the security prices deviate away from their correct values. These mispriced securities create an inefficient market where confidence of traders for fair treatment diminishes. Studies by Ozenbas et al. (2011), Madhavan et al. (1997), and others have documented a U-shaped volatility pattern in developed country stock exchanges. This shape has indicated high volatility and uncertainty in the morning when the market opens, a low and stable volatility during the middle of the trading day, and heightened volatility before the close of the market.

When emerging and frontier country stock markets are examined, research suggests different volatility patterns. For example, Choe and Shin (1993) and Tian and Guo (2007) present L-shaped volatility structures for the morning and for the afternoon trading sessions at the Korean stock exchange and at the Shanghai stock exchange, respectively.

The typical U-shaped intraday volatility pattern seen across many stock market exchanges is also known as the volatility smile. Heightened volatility in the morning is due to the difficulty of market traders in fully digesting the accumulated information overnight. This leads to inconsistent and conflicting trades within the first few minutes, generating accentuated volatility. Heightened volatility before the close of the market can be (1) due to the frantic trading activity of market professionals trying to execute the remaining open orders for the day and/or (2) portfolio rebalancing activities in order to keep the characteristics of these portfolios within the bounds for which they were originally created.

Whatever the reason, accentuated volatility hurts market participants. In highly volatile environments of uncertainty, stocks are not correctly priced, markets are inefficient, and traders are neither fairly nor equally treated. Consequently, the exchange regulators adapt tools and mechanisms to bring social fairness and equality back to the market.

\section{The Volatility Characteristics at Borsa Istanbul}

The volatility features of the Turkish stock exchange have been investigated in previous studies, mainly with low frequency daily, weekly, and monthly data. Alper and Yilmaz (2004) and Erdem et al. (2005) present an empirical analysis of the real stock return volatility contagion from emerging markets and financial centers to the Turkish market since 1992, based on monthly data from January 1991 to January 2004. Bildirici and Ersin (2009) discuss artificial neural networks to evaluate the high volatility of daily returns for the 1987-2008 period in the Istanbul stock exchange.

While the above studies use daily or lower frequency samples, this study employs intraday frequency data with tick-by-tick price movements to get a more relevant picture about volatility during the day. Furthermore, the study centers on the largest and most important industrials sector of the economy. Focusing on the liquid industrials sector, which has more than half of the companies (all actively traded) at Borsa Istanbul provides better insight into the intraday volatility characteristics without unnecessary additional frictions. From these two aspects, this is the first study on the intraday volatility of the industrials sector. The next section provides detailed information about the industrials sector and about the corporate social responsibility mechanisms at Borsa Istanbul. 


\section{BORSA ISTANBUL}

The creation of the Istanbul Stock Exchange (later renamed as Borsa Istanbul) in the early 1980s was followed by the inauguration of the Turkish equity markets in 1986. Since its inception, the exchange has had two trading sessions during the day with a midday break. This is different from the developed country equity markets, where trading is continuous throughout the day. Over the years, the trading hours have changed at Borsa Istanbul but the two sessions in the morning and in the afternoon have remained. Borsa Istanbul Corporation is one of the most vital financial institutions in the Turkish economy.

\section{Corporate Governance, Social Responsibility, Market Efficiency}

As the primary exchange for the regular trading of all financial securities, Borsa Istanbul has established the corporate governance structure and social responsibility principals to make sure that the exchange medium is fair and equal for all market participants. The exchange regulators have implemented numerous mechanisms and policies over the years:

1. With numerous types of orders (limit, market, market to limit, imbalance, conditional, mid-point, odd lot, short-sell, VWAP trades) available for markets participants, the exchange provides convenience and flexibility.

2. Price bands, maximum order value limits, volatility-based measures system, circuit breakers, and market making with continuous auction single prices help with the correct functioning of trading within the financial market.

3. The exchange has numerous authorized independent market advisors.

4. To make sure that there is a reliable and transparent system, unusual price movements, transactions, and trading volumes are monitored and reported through electronic surveillance systems.

\section{Opening Call Auction and Mid-Day Call Auction}

In February 2007, Borsa Istanbul implemented an opening call auction system just before the market opens for the morning session and the afternoon session. The reason has been to collect the accumulated buy and sell orders, and using the order imbalance, to establish an optimal execution price to reduce the uncertainty and the accentuated volatility that have been consistently observed when the market opens in the morning and in the afternoon sessions (Inci, 2012). The reduction in volatility would help establish fair and accurate prices. The opening call auction has been considered as a useful corporate governance mechanism in providing a socially responsible trading environment to market participants.

\section{Closing Time Call Auction System}

On March 2, 2012, Borsa Istanbul introduced a closing auction system. The main reason for this introduction was the high volatility in the stock price movements right before the close of the market for the trading day, and the desire on the part of the administrators to reduce this volatility for fairness and efficiency. The closing auction is a short session with a single price after the exchange formally closes. All unmatched and unexecuted orders of the main trading session and new unmatched orders are compiled during the initial phase of the closing auction. The unique price at which the highest trading volume may be achieved is calculated and all open trades are executed at this price. The usefulness of this policy in the reduction of volatility and the provision of efficiency and fairness to all market participants in the context of the liquid industrials sector is explored next.

\section{Industrials Sector}

The industrials sector makes up more than half of the entire Istanbul stock exchange. The largest sub-sectors in the industrials sector are machinery, chemicals, and construction subsectors. Each of these sub-sectors constitutes about 30 companies. These companies and subsectors are the driving forces of manufacturing and of the export side of the Turkish economy. The other sub-sectors for industrials are textile, 
food, metals, mining, and pulp \& paper \& printing sub-sectors. They contribute significantly to the gross domestic production of the economy.

The primary sources of exports of the Turkish economy originating from the industrials sector are construction, automotive, chemicals, textile, and food products. The industrials sector has been stable enough to insulate the Turkish economy from volatile market conditions and from global shocks. The sector has grown consistently every year in the 2010s and remains as one of the strongest and healthiest sections of the stock exchange (Akgun and Sahin, 2017).

\section{DATA AND METHODOLOGY}

The Borsa Istanbul industrials sector consists of 153 firms [Sector Index: XUSIN]. The subsectors are Food [21 firms, sub-sector index: XGIDA], Textile [13 firms, sub-sector index: XTEKS], Pulp, Paper, and Printing [14 firms, subsector index: XKAGT], Chemicals, Petrol, Plastics [27 firms, sub-sector index: XKMYA], Construction [27 firms, sub-sector index: XTAST], Metals [18 firms, sub-sector index: XMANA], Mining [4 firms, sub-sector index: XMADN]; and Machinery, [29 firms, sub-sector index: XMESY]. The intraday sample in this paper extends from July 2010 through February 2019 and avoids the financial crisis period of 2007-2008. Intraday volatility patterns are examined with this dataset.

The presence of accentuated volatility is explored for the morning session with a focus on the three 5-minute periods when the market opens and the three 5 -minute periods when the market closes for the lunch break. Similarly, for the afternoon session, the three 5-minute periods when the market reopens and the three 5 -minute periods when the market closes for the day are used in the empirical analyses. The middle 5-minutes of the two sessions are also considered. The differences in the volatilities of these intraday time segments are presented with point estimates, statistical tests, and graphical plots.

Trading hours at Borsa Istanbul have evolved over the years. When creating the datasets for the investigation of intraday volatility in the industrials sector, these different opening and closing hours are consistently and jointly considered. For example, when the last 5minute segment of the trading day is explored, that would correspond to 5:55pm-6pm for 14 November 2017 until now, from 5:25pm to 5:30pm during the June 2013 to November 2016 period, and so on. The same approach is followed for all the other 5-minute time segment classifications of the trading day over the sample period.

\section{RESULTS AND DISCUSSION}

The summary statistics of the intraday volatility characteristics for the industrials sector are presented in Table 1. Different volatility measurements using the 5-minute time segments are reported. For both the morning and afternoon sessions, volatilities for the three consecutive opening 5-minute segments, the middle of the session, and the last three consecutive 5-minute segments before the market closes are listed. A quick inspection of the entire 2010-2019 sample reveals that the highest volatility is during the 5-minute segment when the stock market opens in the morning. The second highest volatility is when the market reopens in the afternoon. The third highest volatility is around when the market closes, but this last observation is not supported by all the volatility measures. The potential increase in volatility before the close of the market is possibly harnessed by the closing call auction mechanism that was implemented in March 2012 by the Borsa Istanbul administrators.

The sample period is from July 2010 through February 2019. Each variable in the table represents a different standard deviation measurement: abs is of absolute values of the final and beginning price differences for the period; log is of the log returns in basis points; ret is of the returns expressed in basis points; mad is of the absolute value of end of period and beginning of period price difference normalized by the final price in basis points; maxmin is of the difference between maximum and minimum values of the trading period; and normmaxmin is of the difference between maximum and minimum values of the trading period divided by the average of the final and 
beginning prices of the trading period in basis points.

Table 1. Intraday Volatilities of the Industrials Sector (5-min intervals)

\begin{tabular}{|l|l|l|l|l|l|c|c|}
\hline \multicolumn{1}{|c|}{ 5-Minute Intervals } & $\mathrm{N}$ & abs & log & ret & mad & maxmin & normmaxmin \\
\hline 1st 5 min. & 2156 & 149.83 & 24.42 & 24.43 & 17.20 & 171.14 & 18.20 \\
\hline 2nd 5 min & 2156 & 113.19 & 17.43 & 17.41 & 12.58 & 124.40 & 12.51 \\
\hline 3rd 5 min. & 2156 & 101.50 & 15.81 & 15.81 & 11.18 & 110.78 & 11.06 \\
\hline Mid-morning 5 min. & 2158 & 53.12 & 8.85 & 8.84 & 6.26 & 59.33 & 6.40 \\
\hline 3rd to last 5 min. bef. break & 2153 & 40.36 & 6.96 & 6.95 & 4.86 & 45.18 & 5.09 \\
\hline 2nd to last 5 min. bef. & 2153 & 37.57 & 6.77 & 6.77 & 4.75 & 43.16 & 5.07 \\
break & 2152 & 37.40 & 7.14 & 7.14 & 5.01 & 39.59 & 5.34 \\
\hline Last 5 min. bef. break & 2139 & 103.54 & 16.06 & 16.02 & 12.66 & 108.83 & 12.80 \\
\hline 1st 5 min. after break & 2139 & 80.42 & 12.23 & 12.22 & 8.82 & 86.21 & 8.80 \\
\hline 2nd 5 min after break & 2139 & 59.95 & 10.82 & 10.82 & 7.55 & 65.39 & 7.54 \\
\hline 3rd 5 min. after break & 2141 & 72.36 & 10.05 & 10.06 & 7.48 & 81.35 & 7.95 \\
\hline Mid-afternoon 5 min. & 2141 & 68.48 & 11.20 & 11.19 & 8.02 & 70.05 & 7.93 \\
\hline 3rd to last 5 min. bef. close & 2047 & 68.80 & 11.55 & 11.53 & 8.43 & 70.77 & 8.48 \\
\hline 2nd to last 5 min. bef. close & 2141 & 61.95 & 13.01 & 13.02 & 9.64 & 65.42 & 10.27 \\
\hline Last 5 min. before close & 214 \\
\hline
\end{tabular}

Figure 1 depicts the 5-minute intraday volatilities. We can clearly observe the L-shaped 'smirk' pattern in the volatility during the morning session. The afternoon pattern is not entirely clear. Some volatility measures imply a U-shaped 'smile', while the others indicate an Lshaped 'smirk', similar to that of the morning session. The lack of a consistent pattern for the afternoon session is possibly because of the closing call auction system of March 2012 implemented to reduce volatility and achieve socially responsible fair and efficient pricing which is addressed further in Section 5.1.

Next, volatility ratios are computed to better understand the differences between the opening (closing) volatility values and the midsession volatilities. This approach makes it possible to statistically observe the relative effect of the volatility dynamics throughout the trading day. If the ratio of the opening or closing volatility relative to the mid-session volatility is statistically significant (i.e. if the volatility ratio is statistically higher than one), this would provide concrete evidence of accentuated intraday volatility patterns in the industrials sector. To investigate this issue, the opening (and end of day closing) period-to-midafternoon volatility ratios for each of the risk measures are computed. Similarly, the opening (and end of day closing) period-to-mid-morning volatility ratios are also computed. These volatility ratios are presented in Table 2 . 


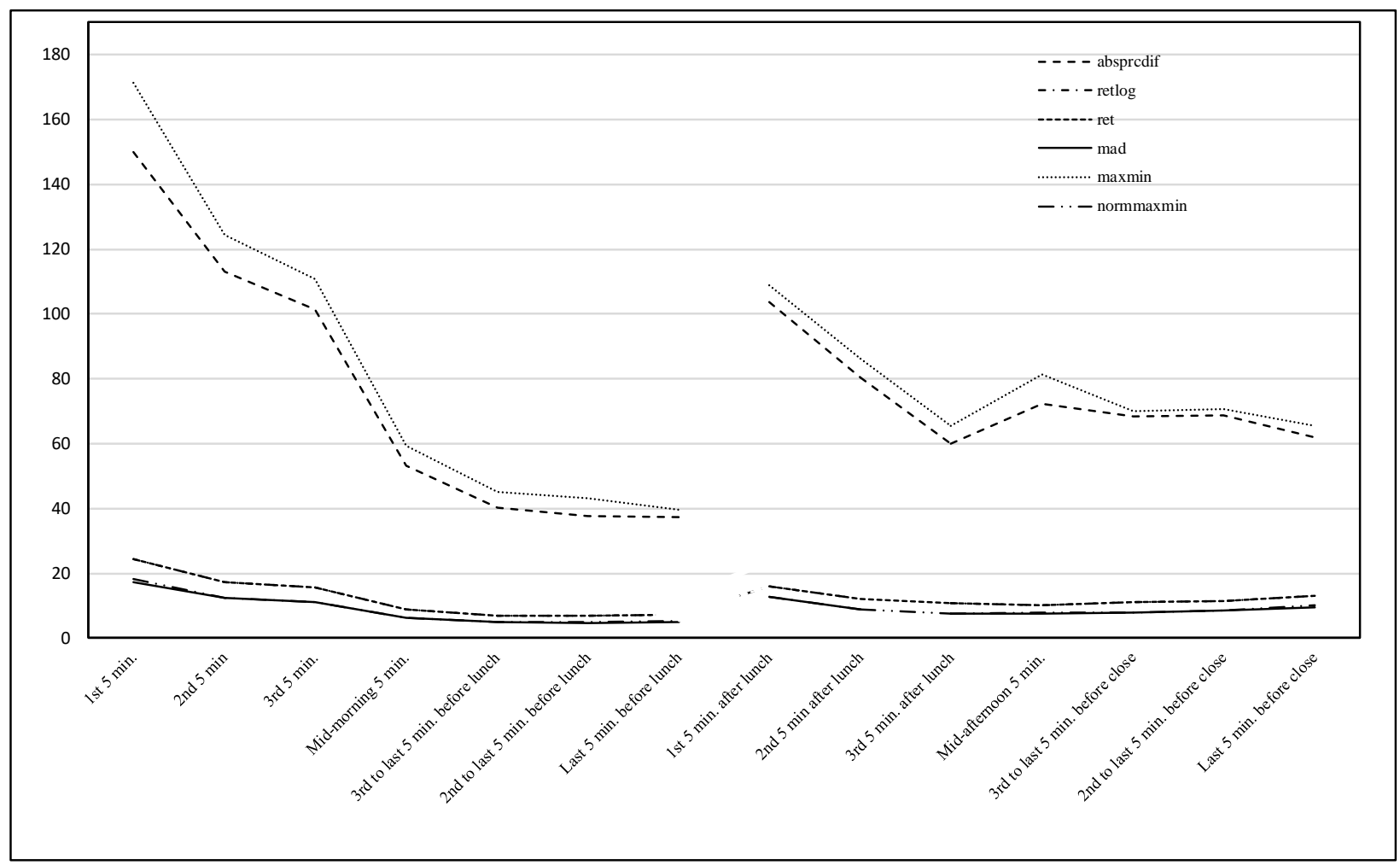

Figure 1. Intraday Volatility at the Borsa Istanbul Industrials Sector

Panel A of Table 2 employs the closing volatilities in the numerator and Panel B employs the opening volatilities in the numerator. Most volatility ratios in the table are greater than one, reflecting the accentuation of volatility when the market opens in the morning and before the market closes for the day. These ratios are further confirmation of accentuated volatility in the industrials sector during the morning open and prior to the market close. Of the results presented in the Panel A (where the closing volatility is in the numerator), some of the ratios are not statistically different from 1 . This is probably because of the closing auction mechanism, mitigating the closing volatility in the numerator of the ratios. The impact of the closing auction is examined next.

\section{Evolution of the Closing Time Volatility}

Borsa Istanbul executives implemented the closing call auction system on March 2, 2012. The purpose was to reduce the accentuated volatility around the closing time of the market for the day. The high volatility caused mispricings, inefficiencies, and the potential mistreatment of some market participants. As an act of good corporate governance and social responsibility, the auction system was introduced. Unexecuted trades after the close of the market would be collected together and buy and sell orders would be matched in order to generate an optimal execution price with the largest trading volume. The presence of such an auction system provided an out for late traders and would therefore reduce accentuated volatility at the end of the day, and thus help provide stability, efficiency, accurate prices, and fairness to the market overall.

To investigate this, the 2010-2019 sample period is split into two sub-samples as the early sub-sample, and the recent sub-sample with the closing auction system. For robustness, the sample was also split into three sub-samples as the early sub-sample before the closing auction system, the middle sub-sample around which the closing call auction was introduced, and the recent sub-sample where the closing auction system was fully established. 
Volatility ratios use the closing period volatility in the numerator and either midmorning or mid-afternoon volatility in the denominator. 5-minute period returns are used for volatility measurements. The standard deviation measures are the same as those in Table $1 . " * *, "$, and "represent the statistical difference of the numerator with respect to the denominator (mid-morning or mid-afternoon volatility) at $1 \%, 5 \%$, or $10 \%$ level. Panel A reports the closing volatility to mid-session volatility ratios and Panel B reports the opening volatility to mid-session volatility ratios. The sample period is from July 2010 through February 2019.

Table 2. Opening and Closing Volatility to Mid-morning and Mid-afternoon Ratios

\begin{tabular}{|l|c|c|}
\hline \multicolumn{3}{|c|}{ 5-minute period returns } \\
\hline \multicolumn{1}{|c|}{$\begin{array}{c}\text { Panel A. Closing } \\
\text { Volatility }\end{array}$} & $\begin{array}{c}\text { Mid- } \\
\text { Morning }\end{array}$ & \multicolumn{1}{c|}{ Mid-Afternoon } \\
\hline abs & $1.17^{*}$ & 0.86 \\
\hline log & $1.47^{* * *}$ & $1.29^{* * * *}$ \\
\hline ret & $1.47^{* * *}$ & $1.30^{* * *}$ \\
\hline mad & $1.54^{* * *}$ & $1.29^{* * *}$ \\
\hline maxmin & 1.10 & 0.80 \\
\hline normmaxmin & $1.60^{* * *}$ & $1.29^{* * *}$ \\
\hline Panel B. Opening & Mid- & Mid- \\
Volatility & Morning & Afternoon \\
\hline abs & $2.82^{* * *}$ & $2.07^{* * *}$ \\
\hline log & $2.76^{* * *}$ & $2.43^{* * *}$ \\
\hline ret & $2.76^{* * *}$ & $2.43^{* * *}$ \\
\hline mad & $2.75^{* * *}$ & $2.30^{* * *}$ \\
\hline maxmin & $2.88^{* * *}$ & $2.10^{* * *}$ \\
\hline normmaxmin & $2.84^{* * *}$ & $2.29^{* * *}$ \\
\hline
\end{tabular}

This table examines the evolution of the closing time volatility over time. In Panel A, Early Sub-Sample is from July 2010 to November 2014, Recent Sub-Sample is from November 2014 to February 2019. In Panel B,
Early Sub-Sample is from July 2010 to June 2013, Middle Sub-Sample is from June 2013 to April 2016, Recent Sub-Sample is from April 2016 to February 2019. The volatility measures are the same as those in Table 1.

Table 3. Effectiveness of Corporate Governance Social Responsibility

\begin{tabular}{|l|l|l|l|l|l|}
\hline Panel A. & $\mathrm{N}$ & $\log$ & ret & mad & normmaxmi \\
\hline Early Sub-Sample & 1071 & 15.72 & 15.74 & 11.60 & 12.03 \\
\hline Recent Sub-Sample & 1070 & 8.88 & 8.89 & 6.04 & 5.87 \\
\hline & & & & & \\
\hline
\end{tabular}




\begin{tabular}{|l|l|l|l|l|l|}
\hline Panel B. & $\mathrm{N}$ & $\log$ & ret & mad & normmaxmi \\
\hline Early Sub-Sample & 720 & 16.68 & 16.72 & 12.80 & 12.96 \\
\hline Middle Sub-Sample & 704 & 10.89 & 10.89 & 7.15 & 7.83 \\
\hline Recent Sub-Sample & 717 & 8.84 & 8.84 & 6.17 & 6.27 \\
\hline
\end{tabular}

Table 3 presents the closing time volatility values for these different sub-samples. As we can see from either panel, after the introduction of the closing call auction system, the volatility measures around the market closing time do indeed decline, implying that the market does become more stable, fair, and efficient with correct stock prices. All of the volatility measures in both panels decline by almost half. Therefore, the success of the closing call auction is evidence that corporate governance is successfully applied, and social responsibility is properly exercised by Borsa Istanbul.

\section{CONCLUSION}

A fundamental corporate social responsibility of a stock exchange is fairness. Every participant in the exchange, individual investor or professional investment company, small investor or a wealthy investor, foreign or domestic, should be treated fairly and equally. This is an important way for an exchange to contribute positively to the welfare of individual participants and to the welfare of the society as a whole.

The volatility patterns for the industrials sector are explored in the study. Accentuated volatility and substantial inefficiency around the closing time of the Turkish stock exchange are documented. These anomalies lead to mispricings and the potential unfair treatment of some market participants. Good corporate governance and social responsibility policies of the Borsa Istanbul Corporation required exchange regulators to find remedies for these types of anomalies.

A particular corporate governance policy of the Borsa Istanbul stock exchange is explored: the introduction of the closing call auction mechanism in March 2012. The aim was to reduce closing time volatility, and therefore mitigate inefficiency and enhance the fair treatment of market participants. The analyses provide evidence of the effectiveness of the policy in the context of the industrials sector of Borsa Istanbul.

The early sub-samples without the proper establishment of the closing call auction system have comparatively high volatility measures around the closing time. However, after the introduction of the closing call auction system, volatility measures become consistently lower in the recent sub-samples. This is evidence of the success of the social responsibility attempt by Borsa Istanbul Corporation. Corporate governance policy of reducing volatility with the closing auction system helps achieve correct prices, efficiency, transparency, fairness and equality for the market participants. These results and conclusions of the closing call auction experience at Borsa Istanbul is an example for other emerging country stock exchanges. If accentuated volatility becomes pervasive, then the closing call auction can be considered as a tool to fight with uncertainty.

\section{REFERENCES}

Abrahamand, S., Kannappan, M. (2018), "The Role of Stock Exchanges in Corporate Governance", International Journal of Pure and Applied Mathematics, 119, 1023-1033.

Alper, C.E., Yilmaz, K. (2004), "Volatility and contagion: evidence from the Istanbul stock exchange", Economic Systems, 28, 353-367.

Akgun, A., Sahin, I.E. (2017), "The Testing of Efficient Market Hypothesis in Borsa Istanbul", Annals of the Constantin Brancusi University of Targu Jiu, 2, 35-48.

Belhaj, F., Abaoub, E., Mahjoubi, M.N. (2015), "Number of Transactions, Trade Size and the Volume-Volatility Relationship: An Interday and Intraday Analysis on the Tunisian Stock Market", International Business Research, 8, 135-152. 
Bildirici, M., Ersin, O.O. (2009), “Improving forecasts of GARCH family models with the artificial neural networks: An application to the daily returns in Istanbul Stock Exchange", Expert Systems with Applications, 36, 7355-7362.

Campbell, J.L. (2007), "Why would corporations behave in socially responsible ways? An Institutional theory of corporate social responsibility", Academy of Management the Academy of Management Review, 32, 946-967

Carroll, A.B. (1999), "Corporate social responsibility", Business and Society, 38, 268-295.

Ching, H.Y., Tardelli, R. (2015), "Cooperate Governance Rules in Six Stock Exchanges: A Comparative Study", Advances in Social Sciences Research Journal, 2, 197-209.

Choe, H., Shin, H.K. (1993), "An Analysis of Interday and Intraday Return Volatility Evidence from the Korea Stock Exchange", Pacific-Basin Finance Journal, 1, 175-188.

Darrat, A.F., Benkato, O.M. (2003), "Interdependence and Volatility Spillovers Under Market Liberalization: The Case of Istanbul Stock Exchange", Journal of Business Finance \& Accounting, 30, 10891114.

Disario, R., Saraoglu, H., McCarthy, J., Li, H. (2008), "Long Memory in the Volatility of an Emerging Equity Market: The Case of Turkey", International Financial Markets, Institutions and Money, 18, 305-312.

El Ghoul, S., Guedhami, O., Kwok, C.C.Y., Mishra, D.R. (2011), "Does corporate social responsibility affect the cost of capital?", Journal of Banking \& Finance, 35, 2388-2406

Erdem, C., Arslan, C.K., Erdem, M.S. (2005), "Effects of macroeconomic variables on Istanbul stock exchange indexes", Applied Financial Economics, 15, 987-994.

Francioni, R., Schwartz, R.A. (2017), Equity Markets in Transition: The Value Chain, Price Discovery, Regulation, and Beyond, Springer, Switzerland.

Friedman, M. (2008), "The Social Responsibility of Business Is to Increase Its Profits",
Multinational Enterprises and Host Economies, 2, 375-380.

Inci, A.C. (2012), "Accentuated Intraday Volatility in Emerging Markets: The Turkish Stock Exchange", Journal of International Finance Studies, 12, 37-52.

Jawadi, F., Louhichi, W., Cheffou, A.I. (2015), "Intraday bidirectional volatility spillover across international stock markets: does the global financial crisis matter?", Applied Economics, 47, 3633-3650.

Kadioglu, E., Kucukkocaoglu, G., Kılıç, S. (2015), "Closing price manipulation in Borsa Istanbul and the impact of call auction sessions", Borsa Istanbul Review, 15, 213221.

Kempf, A., Osthoff, P. (2007), "The effect of socially responsible investing on portfolio performance", European Financial Management, 13, 908-922.

Madhavan, A., Richardson, M., Roomans, M. (1997), "Why do security prices change? A transaction-level analysis of NYSE stocks", Review of Financial Studies, 10, 1035-1064.

Muradoglu, G., Unal, M. (1994), “Weak Form Efficiency in the thinly Traded Istanbul Securities Exchange", Middle East Business and Economic Review, 6, 37-44.

Nassar, S. (2016), "The impact of capital structure on Financial Performance of the firms: Evidence from Borsa Istanbul", Journal of Business and Financial Affairs, 5, 173-176.

Nishimura, Y., Tsutsui, Y., Hirayama, K. (2015), "Intraday return and volatility spillover mechanism from Chinese to Japanese stock market", Journal of the Japanese and International Economies, 35, 23-42.

Ozenbas D., Pagano M.S., Schwartz R.A. (2011), "Accentuated Intraday Stock Price Volatility", In: Schwartz R., Byrne J., Colaninno A. (eds), Volatility. Zicklin School of Business Financial Markets Series. Springer, Boston, MA.

Sarkar, J., Sarkar, S. (2000), "Large Shareholder Activism in Corporate Governance in Developing Countries: Evidence from India", International Review of Finance, 1, 161-194.

Tian, G., Guo, M. (2007), “Interday and Intraday 
Volatility: additional evidence from the Shanghai Stock Exchange", Review of Quantitative Finance and Accounting, 28, 287-306.

Tissaoui, K. (2012), "The Intraday Pattern of Trading Activity, Return Volatility and Liquidity: Evidence from the Emerging Tunisian Stock Exchange", International Journal of Economics and Finance, 4, 156176.

\section{ABOUT THE AUTHORS}

A. Can Inci, email: ainci@bryant.edu

Dr. A. Can Inci is a Professor of Finance, College of Business at Bryant University, Rhode Island, USA. He got his Ph.D. from University of Michigan, Ann Arbor in 2001. He also holds an MBA from Ohio State University, MS in Control Systems from Imperial College - University of London, and $\mathrm{a}$ BS in Electrical and Electronics Engineering from Bogazici University in Istanbul. He has more than 40 publications at Journal of Financial and Quantitative Analysis, Financial Management, Journal of Economic Dynamics and Control, Global Finance Journal, and others. He teaches international finance and business, investments, corporate finance, foundations of financial theory, financial analytics, and financial engineering. $\mathrm{He}$ is the CAIA representative, AACSB consultant and reviewer, and on the editorial board of multiple academic journals. 